\title{
Wax Recovery from the Pyrolysis of Virgin and Waste Plastics
}

Sultan Majed Al-Salem ${ }^{1 *}$, Animesh Dutta ${ }^{2}$

${ }^{1}$ Environment \& Life Sciences Research Centre, Kuwait Institute for Scientific Research, P.O. Box: 24885,

Safat 13109, Kuwait.

2School of Engineering, University of Guelph, Guelph, Ontario N1G 2W1, Canada.

*ssalem@kisr.edu.kw 


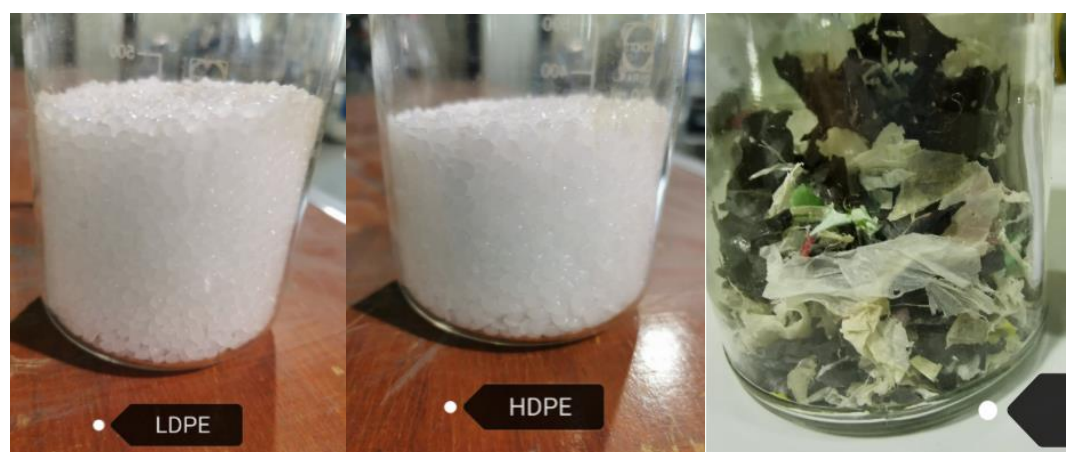

Figure S1. Plastic Grades Used in This Work.

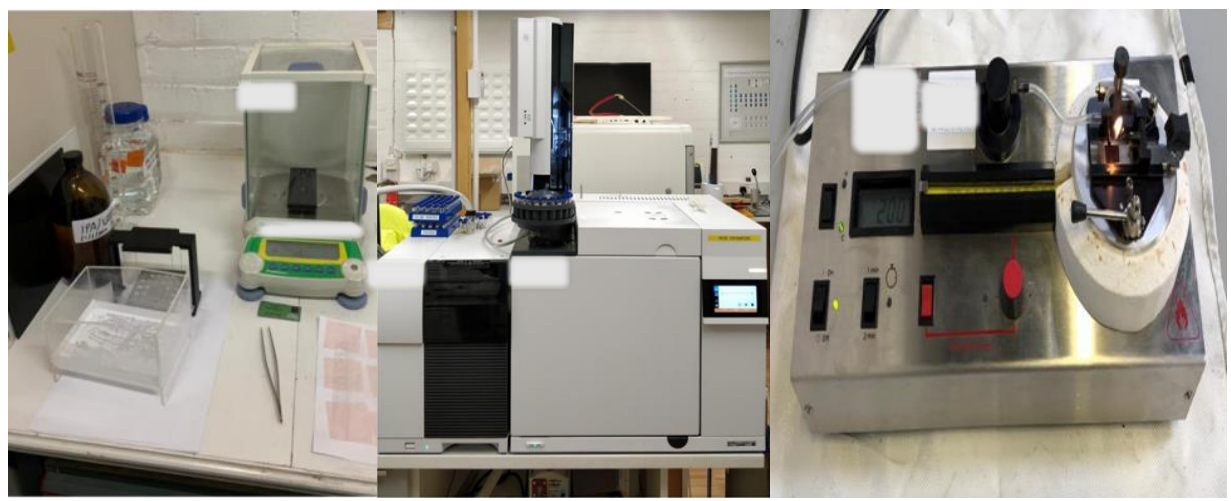

Figure S2. (Left) The Calibrated Specific Gravity Balance used for the analysis of the waxes, (Middle) Gas Chromatograph-Mass Spectrometer used for the compounds screening of the pyrolytic samples; (Right) The Flash Point System Used. Make/Company name was blurred out.

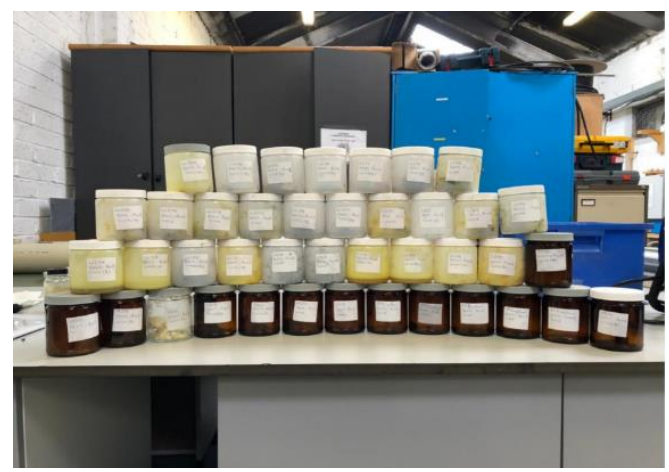

Figure S3. The wax samples as received. 


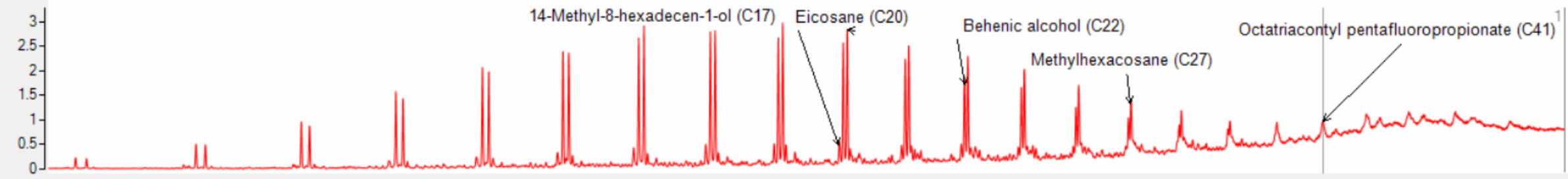

x106 +EI TIC Scan W65AN.D

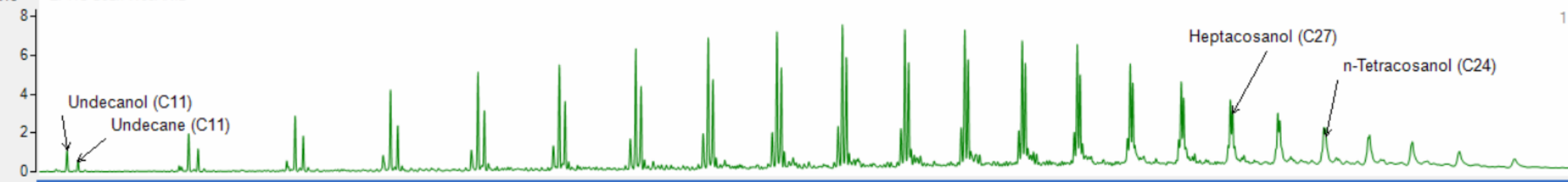

$x 106$ +El TIC Scan W7th 800 C 1.D

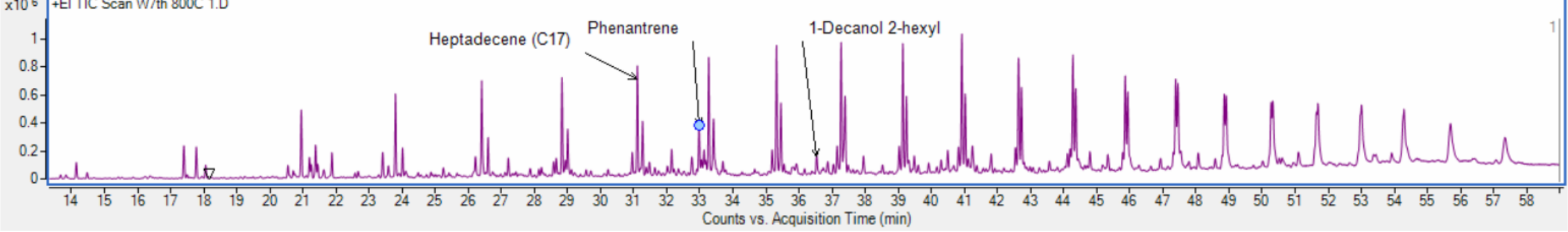

Figure S4. Total lon Chromatograms example from 3 samples, Ex 62B, $65 \mathrm{~A}$ and 7 th Ring road $800^{\circ} \mathrm{C}$, showing the major peaks product of the pyrolysis, which form the typical pattern. 